\title{
Le goût des langues, les langues à l'œuvr, coordinatrices Isa Van Acker et Adina Balint-Babos
}

\section{Chiara Denti}

\section{(2) OpenEdition}

1 Journals

\section{Edizione digitale}

URL: http://journals.openedition.org/studifrancesi/1468

DOI: $10.4000 /$ studifrancesi. 1468

ISSN: 2421-5856

\section{Editore}

Rosenberg \& Sellier

\section{Edizione cartacea}

Data di pubblicazione: 1 décembre 2015

Paginazione: 633

ISSN: 0039-2944

\section{Notizia bibliografica digitale}

Chiara Denti, «Le goût des langues, les langues à l'œuvr, coordinatrices Isa Van Acker et Adina BalintBabos», Studi Francesi [Online], 177 (LIX | III) | 2015, online dal 01 décembre 2015, consultato il 07 janvier 2021. URL: http://journals.openedition.org/studifrancesi/1468 ; DOI: https://doi.org/10.4000/ studifrancesi. 1468

Questo documento è stato generato automaticamente il 7 janvier 2021.

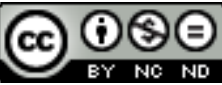

Studi Francesi è distribuita con Licenza Creative Commons Attribuzione - Non commerciale - Non opere derivate 4.0 Internazionale. 


\title{
Le goût des langues, les langues à l'œuvr, coordinatrices Isa Van Acker et Adina Balint-Babos
}

\author{
Chiara Denti
}

\section{NOTIZIA}

Le goût des langues, les langues à l'œuvre, coordinatrices Isa VAN ACKER et Adina BALINTBABOS, 2014, «Les Cahiers J.-M.G. Le Clézio», n. 7, pp. 236.

Il settimo numero della rivista "Cahiers J.-M. G. Le Clézio», pubblicata a Parigi dalle Éditions Complicités, propone una lettura dell'opera di Le Clézio a partire dal tema della lingua, o meglio, delle lingue, come recita il titolo Le goût des langues, les langues à l'œuvre. Obiettivo dichiarato del volume è infatti quello di valorizzare la polifonia e gli elementi di alterità che costellano la lingua di Le Clézio così da portarne alla luce la natura marcatamente meticcia. Ma questo numero si pone sotto il segno della pluralità linguistica anche per l'ampio e ricco spazio riservato alla pratica della traduzione. Proprio i contributi che aprono la prima sezione del volume affrontano il viaggio dell'opera lecleziana verso altre lingue. Il saggio di Naòmi MORGAN (Traduire L'Africain en afrikaans: J.-M.G. Le Clézio en terre inconnue, pp. 23-35), dedicato alla traduzione del romanzo L'Africain in afrikaans - il solo testo di Le Clézio di cui esista una traduzione in questa lingua -, si sofferma tanto sulle sfide traduttive (la traduzione del titolo, tra le altre) quanto sulle fortunate coincidenze che hanno favorito la sua pubblicazione. Nel secondo contributo Oh BOBAE e Kang GEEYE (Réception de l'œuvre de Le Clézio en Corée du Sud, pp. 37-47) spiegano le ragioni del successo riscosso rispettivamente dai romanzi Le Déluge e Poisson d'or in Corea del Sud, per poi addentrarsi in un'analisi puntuale di alcune scelte traduttive. Ancora alla traduzione è dedicato l'intervento di Celeste BRONZETTI ("La Ronde et autres faits divers": des nouvelles polyphoniques et une langue de frontière, pp.91-103) che, alla luce della sua esperienza, richiama l'attenzione sulle 
difficoltà incontrate nel restituire in italiano la lecleziana "lingua di frontiera" - zona di incrocio tra più idiomi e dunque intrinsecamente polifonica. Su questi fecondi intrecci-di lingue e di saperi-si concentrano i saggi di Raymond MBASSI ATEBA (Africanismes et créolismes dans la prose leclézienne, pp. 63-78) e Jean Claude ABADA MEDJO (Langues et savoirs dans l'œuvre de Le Clézio, pp. 105-117) volti a indagare la scrittura eterolinguistica di Le Clézio; sia che si manifesti attraverso l'inserimento di africanismi e creolismi - che si insinuano e penetrano nel francese - sia che si realizzi tramite la mescolanza di lingue e immaginari diversi, l'eterolinguismo del testo lecleziano sottende una presa di posizione per una coesistenza possibile fra lingue, linguaggi e culture. Anche il saggio di Maryam SHEIBANiAn (Effet de l'onomastique exotique dans la réception de la littérature de Le Clézio: "Histoire du pied et autres fantaisies", pp. 49-61) pone l'attenzione sulla presenza di lingue straniere, concentrandosi però in modo specifico sull'onomastica esotica allo scopo di illustrare l'effetto che i nomi propri sconosciuti producono sul lettore. Con Cécile KostLen («L'île des Cygnes, l'île Maurice. Isla Cisneros»: J.M.G. Le Clézio - oiseau migrateur et tisseur de mots, pp. 79-89) il plurilinguismo lecleziano viene affrontato a partire da una dettagliata analisi di una enigmatica frase chiave pronunciata dal narratore alla fine del romanzo Ritournelle de la faim. Questa frase esemplifica efficacemente il modo in cui Le Clézio «manie la langue multiple en tant que voyageur-traducteur» (p. 79). Segue il contributo di Christophe PrEmAT (Retrouver les voix autochtones: l'hommage de Jean-Marie Gustave Le Clézio à Rita Mestokosho, pp.119-133) volto a studiare il legame tra Le Clézio e la poetessa di lingua innu Rita Mestokosho, a cui lo scrittore rende omaggio nel discorso tenuto in occasione della consegna del premio Nobel. Questo intervento chiude la prima parte e insieme conduce alla successiva, interamente dedicata alla creazione, in cui vengono presentati una poesia inedita di Rita Mestokosho e due testi della scrittrice franco-canadese Lise Gaboury-Diallo. Conclude il numero la sezione dal titolo «Témoignages», che raccoglie una serie di interviste condotte dalle curatrici ad alcuni traduttori dell'opera lecleziana (tedesco, svedese, giapponese e cinese); qui gli «artisans de l'ombre» (p. 148) escono allo scoperto: si raccontano e raccontano la "miseria" e lo "splendore" del tradurre Le Clézio.

2 Il volume, coniugando voci diverse e complementari (studiosi, poeti, traduttori), consente al lettore di penetrare nella lingua di Le Clézio a più livelli e di seguirne le migrazioni verso altre lingue. In queste pagine - piace rimarcarlo - viene offerto spazio e visibilità alla traduzione e a chi la pratica; riesce difficile immaginare una scelta più felice per un testo concepito in movimento fra le lingue. 